\title{
Zero-profile implant versus conventional cage-plate implant in anterior cervical discectomy and fusion for the treatment of degenerative cervical spondylosis: a meta-analysis
}

\author{
Haiyu Shao', Jinping Chen ${ }^{1 *}$, Bin Ru', Feifei Yan², Jun Zhang ${ }^{1}$, Shaonan $X u^{1}$ and Yazeng Huang ${ }^{1}$
}

\begin{abstract}
Background: Zero-profile implant has become more and more popular in anterior cervical discectomy and fusion (ACDF) for the treatment of degenerative cervical spondylosis. However, there was no enough evidence judging its efficiency and safety. The aim of this analysis was to evaluate the efficacy and safety of Zero-profile implant compared with conventional cage-plate (CCP) in ACDF.

Methods: All studies directly comparing the outcomes between the Zero-profile implant and CCP implant in ACDF were included, and the search strategy followed the requirements of the Cochrane Library Handbook. Two of the authors extracted relevant data and checked the accuracy independently using standardized data collection form.

Results: Seven studies involving 560 patients were included, 262 in the Zero-profile group and 298 in the CCP group. Zero-profile implant had a lower rate of postoperative dysphagia at 2 weeks, 6 months, and 1 year $(p=0.0002$, $p=0.008$, and $p=0.001$, respectively) than CCP implant. Zero-profile also reduced blood loss $(p=0.0001)$, while operation time and incidence of postoperative transient dysphagia had no statistical significance $(p=0.92, p=0.42$, respectively) between two groups.

Conclusion: Based on the results of our analysis, the application of Zero-profile implant in ACDF had a lower rate of postoperative dysphagia at 2 weeks, 6 months, and 1 year than CCP implant. Zero-profile implant also had fewer blood loss during operation. More rigorous and adequately powered prospective randomized controlled trials with larger sample size are required to elucidate a more objective outcome.
\end{abstract}

Keywords: Zero-profile, Anterior cervical discectomy and fusion, ACDF, Dysphagia, Degenerative cervical spondylosis

\section{Introduction}

Since anterior cervical discectomy and fusion (ACDF) was first described by Smith and Robinson [1], the procedure has become the gold-standard operation for single- or multiple-level degenerative cervical spondylosis. The application of stand-alone cage with a titanium plate (conventional cage-plate (CCP)) in ACDF has become more and more popular since studies [2-5] showed that CCP had many advantages compared with the stand-

\footnotetext{
* Correspondence: y1028263755@126.com

Haiyu Shao, M.D. was the first author.

'Department of Orthopaedics, Zhejiang Provincial People's Hospital, No.158,

Shangtang Road, Hangzhou 310000, Zhejiang, China

Full list of author information is available at the end of the article
}

alone cage: improving sagittal alignment, interbody fusion rate, and stability and preventing interbody graft dislocation. However, complications related to the plates were not rare, such as postoperative dysphagia, adjacent level degeneration, and soft tissue injury [6-8]. And, sometimes, it seems to be inescapable.

Thus, Zero-profile implant was invented to reduce part of the complications. It consisted of a cage and a plant with locking screws which could be fixed into the intervertebral space to keep away from the front tissue $[9,10]$. In the past few years, Zero-p implant has been used more and more wildly since studies [11-13] showed that it had many advantages over CCP implant.

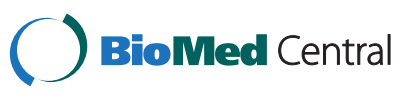

(c) 2015 Shao et al. Open Access This article is distributed under the terms of the Creative Commons Attribution 4.0 International License (http://creativecommons.org/licenses/by/4.0/), which permits unrestricted use, distribution, and reproduction in any medium, provided you give appropriate credit to the original author(s) and the source, provide a link to the Creative Commons license, and indicate if changes were made. The Creative Commons Public Domain Dedication waiver (http://creativecommons.org/publicdomain/zero/1.0/) applies to the data made available in this article, unless otherwise stated. 
The purpose of this analysis was to conduct a metaanalysis of relevant studies directly comparing the Zero-profile implant (Zero-profile group) with CCP implant (CCP group) in ACDF for degenerative cervical spondylosis.

\section{Methods}

Literature search

Electronic databases (Pubmed, EMBASE, Cochrane Central Register of Controlled Trial, and ISI Web of Science) were searched by two independent investigators (BR and FY). Results were last updated on October 2014. Boolean operators were used as follows: (zero-profile OR zero profile OR zero-p OR zero p) AND ((anterior AND fusion AND cervical AND (discectomy OR microdiscectomy OR Discectomies OR Diskectomies)) OR ACDF) with no restriction of publication year and language. We also hand-searched the reference lists of manuscripts included in order to detect other reports not identified by our original search.

\section{Inclusion and exclusion criteria}

Inclusion criteria of degenerative cervical spondylosis were patients with degenerative disease and radiculopathy and/or myelopathy who had not responded to conservative treatment for at least 6 weeks. Exclusion criteria were developmental stenosis, ossification of the posterior longitudinal ligament, and a previous history of cervical spinal surgery.

Two of the authors independently reviewed the titles and abstracts and strictly followed the following inclusion criteria: (1) a direct comparison between the Zero-profile implant and CCP implant in ACDF with clinical and/or radiological outcomes, such as postoperative dysphagia scores, operation time, blood loss, Japanese Orthopaedic Association (JOA) score, visual analog scale (VAS) score, Cobb angle, and so on; (2) prospective, retrospective controlled trial; (3) the participants of the two groups without significant difference in age and gender; and (4) the language was English. Studies without a comparator, editorials, reviews, animal studies, and in vitro studies were excluded.

\section{Data extraction}

Two of the authors extracted relevant data and checked the accuracy independently using standardized data collection form. The extracted data from each study included the following: first author, published year, study design, patient demographics (sample size, age, gender), follow-up time, and outcomes. If the data were not reported in the original article or not displayed in the table, we extrapolated them from the accompanying graphs. We also tried our best to contact the corresponding authors of the eligible trials to get any further useful data for our analysis.
When the two reviewers had disagreements, one or more reviewers joined in discussion until consensus was achieved.

\section{Statistical analysis}

We divided studies into two subgroups, retrospective study subgroup and prospective study group. All data were conducted with RevMan 5.0 analysis software (The Cochrane Collaboration, Copenhagen, Denmark). Odds Ratios (ORs) and $95 \%$ confidence intervals (CIs) were used for the analysis of dichotomous outcomes. For continuous data, weighted mean differences (WMDs) were calculated with $95 \% \mathrm{CI}$ as the summary statistics. A chisquare test and $I^{2}$ test were used to calculate the statistical heterogeneity. We considered $I^{2}$ values of 25,50 , and $75 \%$ as low, medium, and high heterogeneity, respectively. If $I^{2}<50 \%$, we used the fixed-effects model; otherwise, the random-effects model was used. We performed such sensitivity analyses only if there were three or more studies included in the comparison.

\section{Results}

Literature search

Literature search initially yielded 295 relevant citations. After titles and abstracts were reviewed, only eight articles met the criteria for inclusion in the report. And, one of them without eligible data of outcomes was excluded. Finally, seven studies [11-17] that met the predetermined eligibility criteria were included in this meta-analysis. The process of selecting studies was shown in Fig. 1.

\section{Characteristics of included studies}

The characteristics of seven studies were presented in Table 1 . There were two retrospective studies $[13,16]$, two prospective studies [15, 17], one prospective RCT [12], and two retrospective cohort studies [11, 14] with a total of 560 patients, 262 in the Zero-profile group and

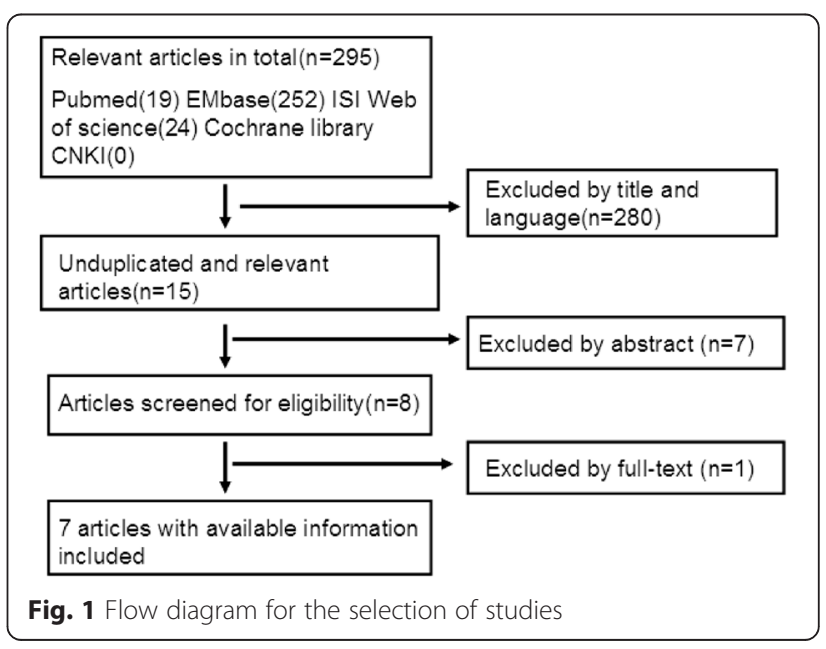


Table 1 Characteristics of the studies included in this meta-analysis

\begin{tabular}{|c|c|c|c|c|c|c|c|c|c|c|}
\hline \multirow[t]{2}{*}{ Study } & \multirow[t]{2}{*}{ Design } & \multicolumn{2}{|c|}{ Sample size (male/female) } & \multirow[t]{2}{*}{$\begin{array}{l}\text { Surgical } \\
\text { level }\end{array}$} & \multicolumn{2}{|c|}{$\begin{array}{l}\text { Mean age } \\
\text { (years) }\end{array}$} & \multirow[t]{2}{*}{ Outcome } & \multicolumn{2}{|c|}{ Follow-up time (m) } & \multirow[t]{2}{*}{ Zero-profile implant } \\
\hline & & Zero-p & CCP & & Zero-p & CCP & & Zero-p & CCP & \\
\hline Wang ZW et al. (2015) [11] & $\begin{array}{l}\text { Retrospective } \\
\text { cohort }\end{array}$ & $30(18 / 12)$ & $33(14 / 19)$ & 1 to 2 & 56.8 & 54 & $\begin{array}{l}\text { Operation time, blood loss, NDI and JOA scores, } \\
\text { Cobb angles, fusion rate, postoperative } \\
\text { dysphagia, adjacent disc degeneration and } \\
\text { instability, cervical lordosis }\end{array}$ & $\begin{array}{l}\text { Mean 24.1, } \\
\text { minimum } 12\end{array}$ & $\begin{array}{l}\text { Mean 23.8, } \\
\text { minimum } 12\end{array}$ & $\begin{array}{l}\text { ROI-C, LDR, Troyes, } \\
\text { France }\end{array}$ \\
\hline Son DK et al. (2014) [13] & Retrospective & 21 & 27 & 1 & 55.4 & 50.2 & $\begin{array}{l}\text { Operation time, blood loss, mJOA and achieved } \\
\text { mJOA scores, mJOA recovery rate, prevertebral } \\
\text { soft tissue thickness, postoperative dysphagia, } \\
\text { adjacent disc degeneration }\end{array}$ & 6 & 6 & $\begin{array}{l}\text { Zero-p; Synthes GmbH, } \\
\text { Oberdorf, Switzerland }\end{array}$ \\
\hline Wang ZD et al. (2014) [16] & Retrospective & $22(11 / 11)$ & $25(10 / 15)$ & 1 & 50.9 & 53.7 & $\begin{array}{l}\text { Operation time, blood loss, JOA scores, JOA } \\
\text { recovery rate, postoperative dysphagia, } \\
\text { adjacent segment degeneration }\end{array}$ & Mean 33.6 & Mean 33.2 & $\begin{array}{l}\text { Zero-p; Synthes GmbH, } \\
\text { Oberdorf, Switzerland }\end{array}$ \\
\hline Li YB et al. (2013) [12] & $\begin{array}{l}\text { Prospective, } \\
\text { RCT }\end{array}$ & $23(9 / 14)$ & $23(13 / 10)$ & 1 & 49.3 & 50.1 & $\begin{array}{l}\text { Operation time, blood loss, exposure time to } \\
\text { X-rays, JOA and VAS scores, postoperative } \\
\text { dysphagia, fusion time, adjacent disc } \\
\text { degeneration }\end{array}$ & 24 & 24 & $\begin{array}{l}\text { Zero-p; Synthes GmbH, } \\
\text { Oberdorf, Switzerland }\end{array}$ \\
\hline Qi M et al. (2013) [14] & $\begin{array}{l}\text { Retrospective } \\
\text { cohort }\end{array}$ & $83(47 / 36)$ & $107(58 / 49)$ & 1 to 3 & 43.6 & 44.9 & $\begin{array}{l}\text { Operation time, blood loss, NDI and VAS scores, } \\
\text { fusion rate, graft migration or nonunion, Cobb } \\
\text { angles, modified Swallowing Quality of Life } \\
\text { scores }\end{array}$ & Mean 18.6 & Mean 19.3 & $\begin{array}{l}\text { Zero-p; Synthes GmbH, } \\
\text { Oberdorf, Switzerland }\end{array}$ \\
\hline Vanek P et al. (2013) [15] & Prospective & $44(26 / 18)$ & $33(19 / 14)$ & 1 to 2 & 50.2 & 51.8 & $\begin{array}{l}\text { NDI scores, Cobb C and Cobb S angles, 2-year } \\
\text { radiological stability, dysphagia }\end{array}$ & Minimum 24 & Minimum 24 & $\begin{array}{l}\text { Zero-p; Synthes GmbH, } \\
\text { Oberdorf, Switzerland }\end{array}$ \\
\hline Miao JH et al. (2013) [17] & Prospective & $39(23 / 16)$ & $50(29 / 21)$ & 1 to 3 & 50.3 & 52.6 & $\begin{array}{l}\text { JOA and VAS scores, postoperative dysphagia, } \\
\text { Cobb angles, 1-year operation effect, implant } \\
\text { displacement, and vertebral instability }\end{array}$ & Mean 16.9 & & $\begin{array}{l}\text { Zero-p; Synthes GmbH, } \\
\text { Oberdorf, Switzerland }\end{array}$ \\
\hline
\end{tabular}


298 in the CCP group. The number of surgical level ranged from 1 to 3 . There were no statistically significant differences for patient age, gender, and number of surgical level of all seven studies. The clinical outcomes mainly included operation time, blood loss, pre- and postoperative JOA scores, and postoperative dysphagia. And, the radiological outcomes mainly included pre- and postoperative Cobb angles, VAS scores, adjacent disc degeneration, and neck disability index (NDI). The mean follow-up time was more than 6 months.

\section{Meta-analysis results Operation time}

Five studies $[11-14,16]$ reported operation time of one level. One of the five studies [12] divided patients of both the Zero-profile group and CCP group into radiculopathy and myelopathy subgroups. We combined the data from the two subgroups using the formula below:

Mcombined $=\frac{N_{1} M_{1}+N_{2} M_{2}}{N_{1}+N_{2}}$

SDcombined

$$
=\sqrt{\frac{\left(N_{1}-1\right) \mathrm{SD}_{1}^{2}+\left(N_{2}-1\right) \mathrm{SD}_{2}^{2}+\frac{N_{1} N_{2}}{N_{1}+N_{2}}\left(M_{1}^{2}+M_{2}^{2}-2 M_{1} M_{2}\right)}{N_{1}+N_{2}-1}}
$$

Three studies $[11,14,16]$ showed that the Zeroprofile implant could reduce operation time compared with CCP implant. However, the other two [12, 13] demonstrated contrary results. All data were pooled to make a meta-analysis. Due to the high heterogeneity $\left(I^{2}=92 \%\right.$, $p<0.00001)$, we chose the random-effects model. We found that there was no significant difference in operation time $(n=214, p=0.38)$ between the Zero-profile group and CCP group (Fig. 2).

\section{Blood loss}

Four studies [11-13, 16] reported the blood loss of one-level surgery. Again, one of them [12] divided patients of both the Zero-profile group and CCP group into radiculopathy and myelopathy subgroups. We combined the data from the two subgroups using the formula described above. We chose the random-effects model to combine the result due to the heterogeneity $\left(I^{2}=23 \%\right)$. Figure 3 presents that Zero-profile implant had a statistical significance $(n=173, p=0.0001)$ reducing blood loss, when compared with CCP implant.

\section{Postoperative dysphagia}

Three studies [13-15] reported postoperative day dysphagia, three studies $[11,13,16]$ reported dysphagia at 2 weeks postoperative, four studies [13, 14, 16, 17] reported dysphagia at 6 months postoperative, and four studies $[11,12,15,17]$ reported dysphagia at 1 year postoperative. Due to the low heterogeneity $\left(I^{2}=0 \%\right)$, we chose the fixed-effects model to combine the results. We found that the Zero-profile group had lower risk of postoperative dysphagia at 2 weeks $(n=158, p=0.0002), 6$ months $(n=275, p=0.008)$, and 1 year $(n=374, p=0.001)$, except postoperative day $(n=315, p=0.42)$ as shown in Figs. 4,5 , 6 , and 7 .

\section{Other outcomes}

There were less than three studies that reported the same outcomes or there were three or more studies that reported the same outcomes, but they were not of the same time, which made the results incomparable. So, we were unable to compare the operation time of two levels and three levels, JOA recovery rate, JOA, NDI, VAS scores, postoperative dysphagia of 2 and 3 months, fusion rate, Cobb angles, and other outcomes of Zero-profile implant and CCP implant in this analysis.

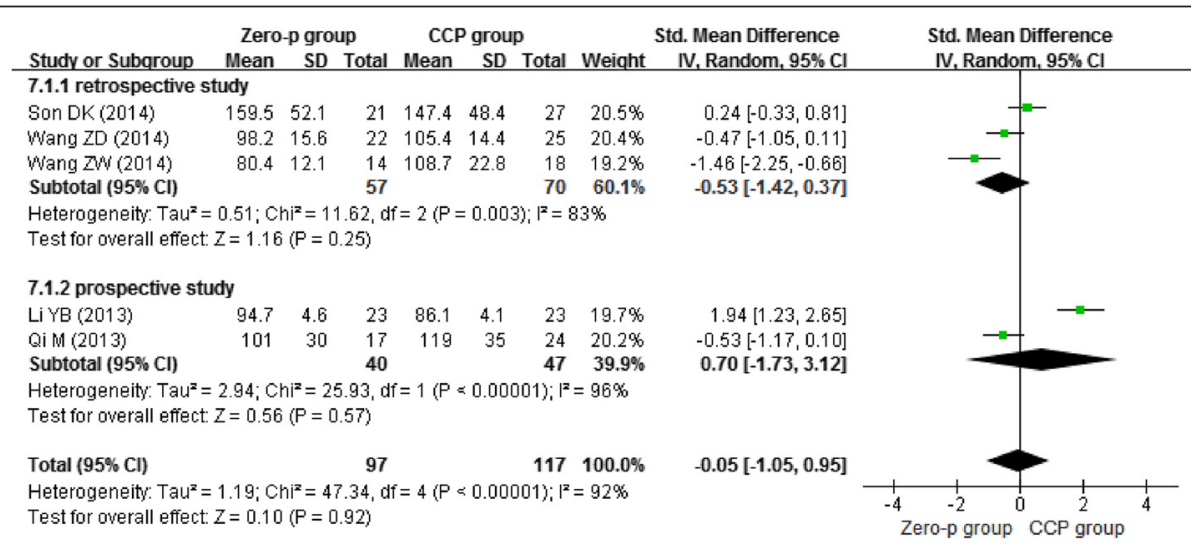

Fig. 2 Forest plot of operation time of one level between the Zero-p group and CCP group 


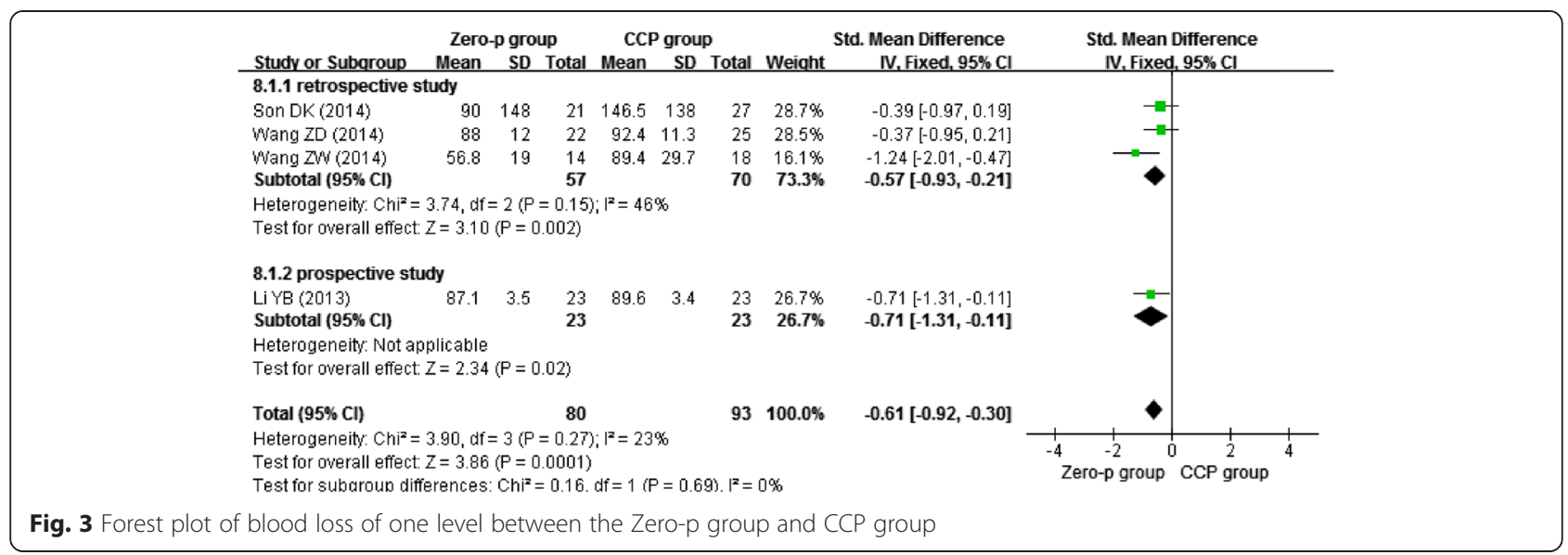

\section{Discussion}

In the past several decades, there were many studies which suggested that CCP implant had many advantages compared with stand-alone cage. But, the application of anterior cervical plate may face with some complications. Esophageal injury, soft tissue compression, and adhesion caused by the anterior plant could lead to neck pain, hoarseness, and dysphagia [18-20]. Bazaz et al. [21] found a high dysphagia incidence of 50.2, 32.2, 17.8, and $12.5 \%$ at $1,2,6$, and 12 months postoperative, respectively. Lee et al. [22] found that a thinner and smoother plant could reduce dysphagia incidence postoperative significantly by means of less touch to the soft tissue precervical.

To lessen potential complications while maintaining the benefits of anterior cervical plate, the Zero-profile implant was invented. Zero-profile implant is a kind of device that contains a stand-alone cage and several angle-controlled screws, which can be implanted into the intervertebral space. The screws could get into the vertebral body through the endplate, and they provide adequate stability and avoid the implant contact to the soft tissue precervical. These unique structures offer a fixation mechanism that is similar to the function of a plate and screws. Since Zero-p implant of Synthes GmbH Switzerland was approved by the US Food and Drug Administration in 2008, many studies have engaged in comparing the outcomes between the Zero-profile implant and CCP implant in order to pursue the optimal implant in ACDF for degenerative cervical spondylosis patients. However, the inconclusive debate still remains.

In this analysis, we focused on objectively comparing the operation time, blood loss, and postoperative dysphagia between the Zero-profile implant (both contain the Zero-p of Synthes GmbH Switzerland and ROI-C of France) and CCP implant in ACDF.

The design of Zero-profile implant avoids the need for any additional internal fixation implants and theoretically circumvents the aforementioned complications

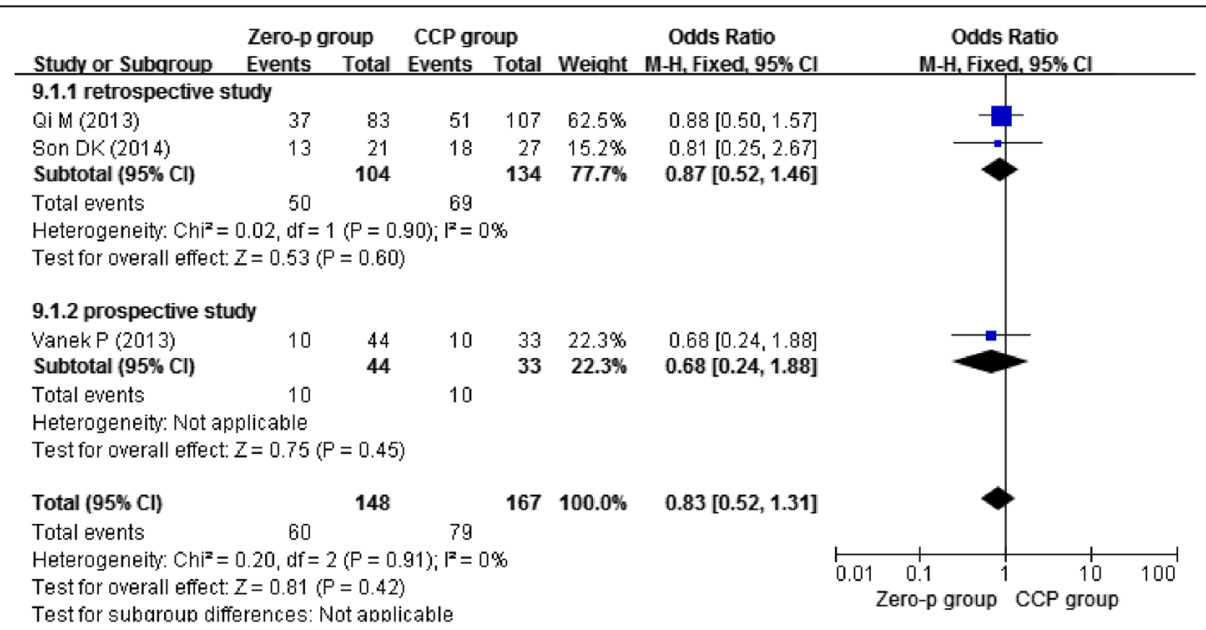

Fig. 4 Forest plot of dysphagia at postoperative day between the Zero-p group and CCP group of all levels 


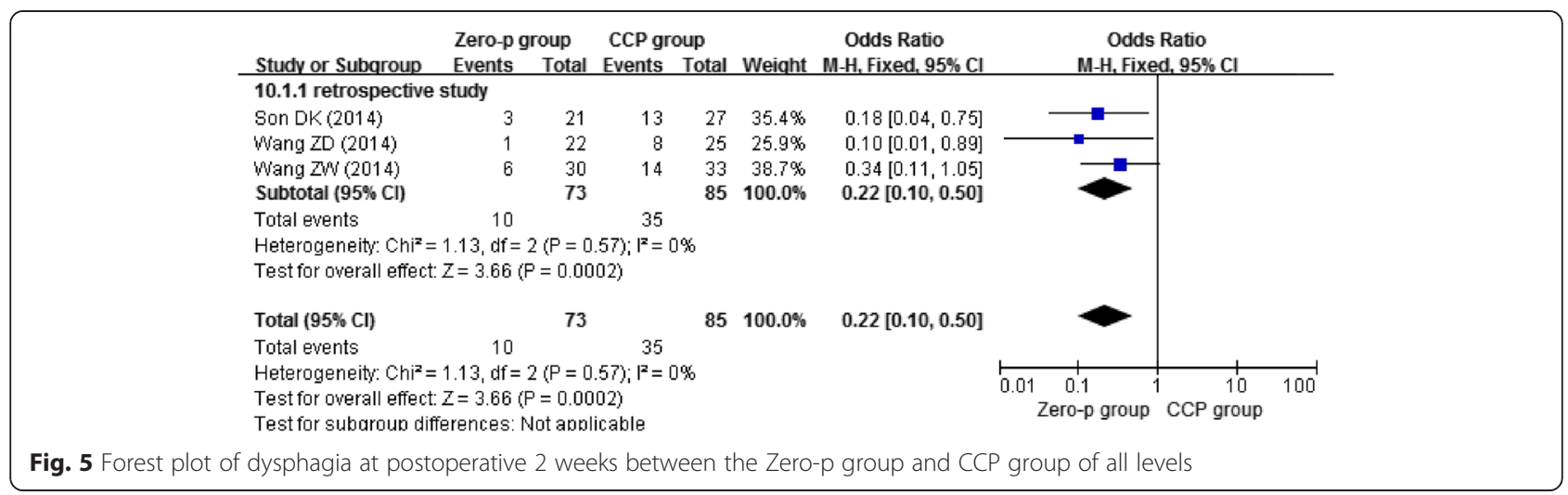

associated with anterior plate while providing the segmental rigidity necessary for cervical spine fusion. In recent years, some studies have evaluated the safety and efficacy of Zero-profile implant. Njoku et al. [23] reported that Zero-profile implant had comparable pain outcomes, functional outcomes, and radiographic fusion rates with CCP implant. Barbagallo et al. [24] found that Zero-profile implant had a significant improvement on outcomes such as NDI scores, postoperative dysphagia, and fusion time. And, Scholz et al. [10] showed that all patients had a reduction on VAS pain, and the incidence of chronic dysphagia was lower than the current literature, which indicated good outcomes of Zero-profile implant. Meanwhile, some studies [11-17, 25] directly compared the clinical and radical outcomes of Zero-profile implant with $\mathrm{CCP}$ implant in ACDF, which could provide better evidence for comparing Zero-profile implant with CCP implant.

Thus, in this meta-analysis, we summarized the current evidences about the operation time, blood loss, and postoperative dysphagia comparing Zero-profile implant with CCP implant. After integrating the results, we found that Zero-profile implant had advantages in reducing the incidence of postoperative dysphagia at 2 weeks, 6 months, and 1 year $(p=0.0002, p=0.008$, and $p=0.001$, respectively) compared with $\mathrm{CCP}$ implant.

Although the exact pathophysiologic mechanism of dysphagia remains unknown, according to Fountas et al. [8], esophageal injury, postoperative soft tissue edema, adhesive formations around implanted cervical plates, and postoperative hematoma may be the possible explanations for dysphagia-related symptoms. The Zero-profile implant can be completely contained in the decompressed intervertebral space, not placed across the anterior vertebral body, avoiding the stimulus to the esophagus and other prevertebral soft tissues, preserving as many normal anatomical tissues as possible. Although it might not be clinically relevant, we still can find significant difference in blood loss $(p=0.0001)$ between the Zero-profile implant and CCP implant. This is possibly because fewer steps are 


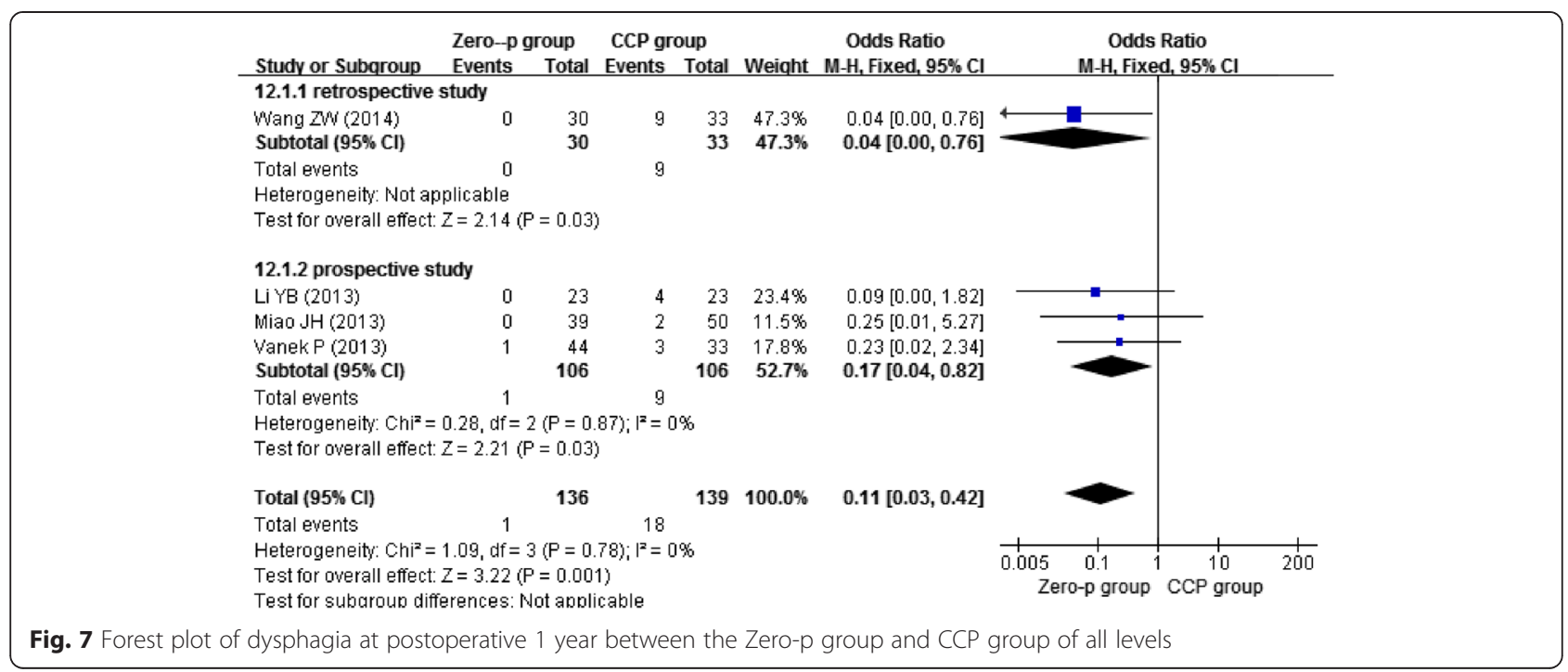

needed to insert the Zero-profile implant, which has a one-step locking mechanism with simple insertion of the cage and tightness of the screws. The Zero-p device has a smaller volume than the CCP implant, which allows a smaller incision. The smaller incision allows more limited resection and less exposure and avoids mechanical stimulus to the related structures [13].

To the best of our knowledge, our analysis is the first meta-analysis to evaluate the efficiency and safety of Zero-profile implant compared with CCP implant in ACDF. It combines the results of existing studies and makes the results more practical. In this way, it may reduce the effect of publication bias. Moreover, the results are encouraging. Zero-profile implant may be a viable alternative in ACDF for degenerative cervical spondylosis patients.

We acknowledge limitations such as the following: (1) the inclusion of both retrospective and prospective studies, random and nonrandom studies; (2) only seven studies were included, and their sample sizes were relatively small; and (3) not all main outcomes were analyzed in the analysis, such as JOA scores, Cobb angles, NDI scores, and fusion rate. These all could lead to bias and reduce the level of evidence in our analysis. (4) As listed in Fig. 1, our study contained two kinds of Zero-profile devices. Although they were of similar mechanism and structure, it may affect the results.

\section{Conclusion}

Based on the results of our analysis, Zero-profile implant can reduce the incidence of postoperative dysphagia at 2 weeks, 6 months, and 1 year and reduce blood loss compared with CCP implant. It cannot reduce the operation time. In summary, the application of Zeroprofile implant is superior to CCP implant in ACDF.
Given possible biases in our study, more rigorous and adequately powered prospective randomized controlled trials with long-term follow-ups are required to elucidate a more objective outcome.

\section{Abbreviations}

ACDF: anterior cervical discectomy and fusion; CCP: conventional cage-plate; JOA: Japanese Orthopaedic Association; mJOA: modified JOA; NDI: neck disability index; VAS: visual analog scale.

\section{Competing interests}

The authors declare that they have no competing interests.

\section{Authors' contributions}

HYS conceived of the design of the study. BR, FFY, and JZ performed the study, collected the data, and contributed to the design of the study. BR, FFY, and SNX prepared the manuscript. HYS, YZH, and JPC edited the manuscript. All authors read and approved the final manuscript.

\section{Acknowledgements}

This study was supported by grants from the Natural Science Foundation of Zhejiang Provincial (CN) (LY14H060006) and Chinese Medicine Research Program of Zhejiang Province (CN) (2015114820). We thank all the corresponding authors from the included trials for their kind assistance in obtaining the additional data that contributed to our meta-analysis.

\section{Author details}

${ }^{1}$ Department of Orthopaedics, Zhejiang Provincial People's Hospital, No.158, Shangtang Road, Hangzhou 310000, Zhejiang, China. ${ }^{2}$ Department of Medicine, Zhejiang University, No.268, Kaixuan Road, Hangzhou 310000, Zhejiang, China.

Received: 10 July 2015 Accepted: 7 September 2015 Published online: 17 September 2015

\section{References}

1. Smith GW, Robinson RA. The treatment of certain cervical-spine disorders by anterior removal of the intervertebral disc and interbody fusion. J Bone Joint Surg Am. 1958;40-A(3):607-24.

2. Song KJ, Taghavi CE, Lee KB, Song JH, Eun JP. The efficacy of plate construct augmentation versus cage alone in anterior cervical fusion. Spine. 2009;34(26):2886-92. doi:10.1097/BRS.0b013e3181b64f2c.

3. Kaiser MG, Haid Jr RW, Subach BR, Barnes B, Rodts Jr GE. Anterior cervical plating enhances arthrodesis after discectomy and fusion with cortical allograft. Neurosurgery. 2002;50(2):229-36. discussion 36-8. 
4. Moon HJ, Kim JH, Kim JH, Kwon TH, Chung HS, Park YK. The effects of anterior cervical discectomy and fusion with stand-alone cages at two contiguous levels on cervical alignment and outcomes. Acta Neurochir. 2011;153(3):559-65. doi:10.1007/s00701-010-0879-z.

5. Pitzen TR, Chrobok J, Stulik J, Ruffing S, Drumm J, Sova L, et al. Implant complications, fusion, loss of lordosis, and outcome after anterior cervical plating with dynamic or rigid plates: two-year results of a multi-centric, randomized, controlled study. Spine. 2009;34(7):641-6. doi:10.1097/ BRS.0b013e318198ce10.

6. Park JB, Cho YS, Riew KD. Development of adjacent-level ossification in patients with an anterior cervical plate. J Bone Joint Surg Am. 2005;87(3):558-63. doi:10.2106/JBJS.C.01555.

7. Zhong ZM, Jiang JM, Qu DB, Wang J, Li XP, Lu KW, et al. Esophageal perforation related to anterior cervical spinal surgery. J Clin Neurosci. 2013;20(10):1402-5. doi:10.1016/j.jocn.2012.11.020.

8. Fountas KN, Kapsalaki EZ, Nikolakakos LG, Smisson HF, Johnston KW, Grigorian $\mathrm{AA}$, et al. Anterior cervical discectomy and fusion associated complications. Spine. 2007;32(21):2310-7. doi:10.1097/BRS.0b013e318154c57e.

9. Cain CM, Schleicher P, Gerlach R, Pflugmacher R, Scholz M, Kandziora F. A new stand-alone anterior lumbar interbody fusion device: biomechanical comparison with established fixation techniques. Spine. 2005;30(23):2631-6.

10. Scholz M, Schnake KJ, Pingel A, Hoffmann R, Kandziora F. A new zero-profile implant for stand-alone anterior cervical interbody fusion. Clin Orthop Relat Res. 2011;469(3):666-73. doi:10.1007/s11999-010-1597-9.

11. Wang ZW, Jiang W, Li X, Wang H, Shi J, Chen J, et al. The application of zero-profile anchored spacer in anterior cervical discectomy and fusion. Eur Spine J. 2015;24(1):148-54. doi:10.1007/s00586-014-3628-9.

12. Li YB, Hao D, He B, Wang $X$, Yan L. The Efficiency of zero-profile implant in anterior cervical discectomy fusion: a prospective controlled long-term follow-up study. Journal of spinal disorders \& techniques. 2013. doi:10.1097/BSD.0000000000000032.

13. Son DK, Son DW, Kim HS, Sung SK, Lee SW, Song GS. Comparative study of clinical and radiological outcomes of a zero-profile device concerning reduced postoperative Dysphagia after single level anterior cervical discectomy and fusion. J Korean Neurosci. 2014;56(2):103-7. doi:10.3340/jkns.2014.56.2.103.

14. Qi M, Chen H, Liu Y, Zhang Y, Liang L, Yuan W. The use of a zero-profile device compared with an anterior plate and cage in the treatment of patients with symptomatic cervical spondylosis: a preliminary clinical investigation. Bone Joint J. 2013;95-B(4):543-7. doi:10.1302/0301-620X.95B4.30992.

15. Vanek P, Bradac O, Delacy P, Lacman J, Benes V. Anterior interbody fusion of the cervical spine with Zero-P spacer: prospective comparative study-clinical and radiological results at a minimum 2 years after surgery. Spine. 2013:38(13):E792-7. doi:10.1097/BRS.0b013e3182913400.

16. Wang ZD, Zhu RF, Yang HL, Gan MF, Zhang SK, Shen MJ, et al. The application of a zero-profile implant in anterior cervical discectomy and fusion. J Clin Neurosci. 2014;21(3):462-6. doi:10.1016/j.jocn.2013.05.019.

17. Miao JH, Shen $Y$, Kuang $Y$, Yang L, Wang $X$, Chen $Y$, et al. Early follow-up outcomes of a new zero-profile implant used in anterior cervical discectomy and fusion. J Spinal Disord Tech. 2013;26(5):E193-7. doi:10.1097/BSD.0b013e31827a2812.

18. Sahjpaul RL. Esophageal perforation from anterior cervical screw migration. Surg Neurol. 2007;68(2):205-9. doi:10.1016/j.surneu.2006.09.032. discussion 9-10.

19. Yue WM, Brodner W, Highland TR. Persistent swallowing and voice problems after anterior cervical discectomy and fusion with allograft and plating: a 5- to 11-year follow-up study. Eur Spine J. 2005;14(7):677-82. doi:10.1007/s00586-004-0849-3.

20. Rhyne 3rd AL, Spector LR, Schmidt GL, Madigan L, Odum SM, Darden 2nd $\mathrm{BV}$, et al. Anatomic mapping and evaluation of the esophagus in relation to the cervical vertebral body. Eur Spine J. 2007;16(8):1267-72. doi:10.1007/s00586-007-0339-5

21. Bazaz R, Lee MJ, Yoo JU. Incidence of dysphagia after anterior cervical spine surgery: a prospective study. Spine. 2002;27(22):2453-8. doi:10.1097/01.BRS.0000031407.52778.4B.

22. Lee MJ, Bazaz R, Furey CG, Yoo J. Influence of anterior cervical plate design on Dysphagia: a 2-year prospective longitudinal follow-up study. J Spinal Disord Tech. 2005;18(5):406-9.

23. Njoku Jr I, Alimi M, Leng LZ, Shin BJ, James AR, Bhangoo S, et al. Anterior cervical discectomy and fusion with a zero-profile integrated plate and spacer device: a clinical and radiological study: clinical article. J Neurosurg Spine. 2014;21(4):529-37. doi:10.3171/2014.6.SPINE12951.

24. Barbagallo GM, Romano D, Certo F, Milone P, Albanese V. Zero-P: a new zero-profile cage-plate device for single and multilevel ACDF. A single institution series with four years maximum follow-up and review of the literature on zero-profile devices. Eur Spine J. 2013;22 Suppl 6:S868-78. doi:10.1007/s00586-013-3005-0.

25. Hofstetter CP, Kesavabhotla K, Boockvar JA. Zero-profile anchored spacer reduces rate of dysphagia compared with ACDF with anterior plating. J Spinal Disord Tech. 2015;28(5):E284-90. doi:10.1097/BSD.0b013e31828873ed.

\section{Submit your next manuscript to BioMed Central and take full advantage of:}

- Convenient online submission

- Thorough peer review

- No space constraints or color figure charges

- Immediate publication on acceptance

- Inclusion in PubMed, CAS, Scopus and Google Scholar

- Research which is freely available for redistribution 